Brit. J. prev. soc. Med. (1974), 28, 203-209

\title{
The economics of general practice in England*
}

\author{
NORMAN GLASS $\dagger$ \\ Medical Care Research Unit, University of Newcastle upon Tyne
}

\section{INTRODUCTION}

In this paper I should like to take up the following topics:

1. What are the implications of the number and distribution of general practitioners for the use of the National Health Service (NHS)?

2. What are the implications of the system of remuneration for general practice organization and for the behaviour of general practitioners?

3. What is the effect of time and distance on the way in which patients (consumers) use the NHS and can this enable us to derive a value for general practitioner services?

It will be almost entirely fortuitous if these three topics fail to overlap at all but I shall make a conscientious effort to prevent them from doing so.

\section{Numbers AND DistribUTION}

The number of general practitioners in the NHS has risen slowly since 1948 . Believed to have been about 18,000 (in England and Wales) in 1948, there were 20,600 in 1971 . The movement was not always upwards year by year-there was a slight fall in the mid-60s-but in general the tendency has been for the numbers to increase. As a proportion of all doctors in the NHS, however, general practitioners have fallen from $60 \%$ to $46 \%$.

The normal practice, in discussing the supply of family doctors, is to talk in terms of list size, that is, the ratio of NHS patients to general practitioners. The average list size for England and Wales fell slowly from 2,400 to under 2,300 in the fifties and early sixties and then rose again to nearly 2,500 in 1969. It has begun to fall again in recent years.

The distribution of general practitioners around the country has always been a matter of policy concern, although it is probably true to say that in the early years of the NHS the distribution of hospital specialists was of more immediate interest. List sizes have ranged from 3,000 or more in parts of the East Midlands, Lancashire, and Durham to about 2,000 in the south-west and other largely rural areas, and this sort of spread has been a fairly constant feature of the NHS (DHSS).

So much for the statistics-but have these numbers any more significance? What do they tell us about the type of care which the general practitioner provides? There has been a general tendency, when discussing general practice, to adopt the slogan 'Short lists good-Long lists bad'. This, of course, is to commit the elementary error of confusing inputs with outputs. General practitioners are 'inputs'. Improved medical care (or, perhaps, better health or something vaguer than that) is what we want. Unless it can be shown that more general practitioners per 1,000 of the population are conducive to better medical care then more inputs may not mean more output.

The evidence concerning the relationship between list size and the care provided by general practitioners is surprisingly limited and difficult to interpret (Clarke, 1971). It is notorious that the rate at which patients consult their family doctors varies widely. Nevertheless it is clear from the work of Wright (1968) and Cartwright (1967) that there is a relationship between list size and rate of consultation. This is illustrated by a table taken from Present State and Future Needs of General Practice (Council of the RCGP, 1973).

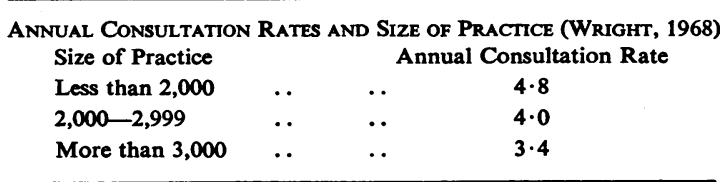

Here it seems that we have some measure of the effect of list-size on, at any rate, one aspect of the use of general practitioner services. 
The usual interpretation of these results is that since a significant proportion of the average doctor's consultations are doctor-initiated, general practitioners have a large amount of control over their volume of work and are able to adjust the number of consultations to accord with the length of time they wish to work.

Another possible interpretation is that either through increases in appointment waiting-times or waiting-times in surgery or through some mysterious interaction between practitioner and patient an understanding grows up of the appropriate threshold at which to consult the doctor, and this threshold is higher for practices with longer lists.

Both of these explanations are rejected by Cartwright, who puts forward the argument that the phenomenon arises because practitioners whose patients do not consult them frequently take more patients on to their list. By implication, increasing the number of practitioners or altering their distribution would not lead to any rise in the overall number of consultations-everyone has as many consultations as he wants.

The argument does not seem too convincing. It conflicts with evidence from other sections of the health and social services, such as the hospitals, the ambulance service, and residential accommodation where the phenomenon of increased provision leading to increased take-up of the services is well known. Furthermore, it carries the implication that regional differences in the numbers of general practitioners are due not to doctors' preferences for different parts of the country but to patients' 'needs'.

If one accepts the first hypothesis that the supply of general practitioners affects the use of their services, that is, the number of consultations, then obviously the next question is: suppose the National Health Service were to spend money to increase the number of general practitioners or to alter their distribution between areas, what would it be getting for its money? What are the extra consultations for, who gets them, and why?

In the absence of any meaningful measure of the output of general practice, information describing the added services which are provided at the margin (in this case the extra consultations) is essential in deciding how many extra general practitioners one should have or how far one should go in attempting to equalize their distribution.

The implication here is that the 'value' of extra consultations falls as the number of consultations increases while the cost of extra general practitioners or of altering the distribution of general practitioners eventually rises.

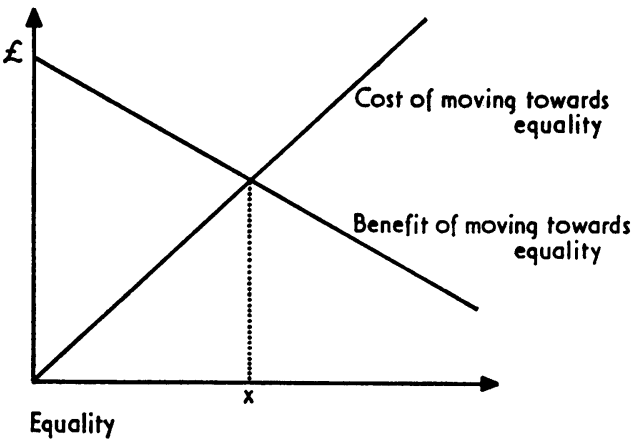

Frg. 1. Costs and benefits of equal distribution.

This is illustrated in Figure 1. It is assumed that the cost of achieving equality of distribution of general practitioners (however defined) rises as one approaches absolute equality. The incentives necessary to persuade the last general practitioner to move from the south-west to the East Midlands may be almost infinite. As the number of general practitioners increases in the relatively under- 8 doctored areas and the more serious discrepancies in standards of service are overcome, the benefits to be derived from moving further towards equality? decline. At some point (point $\mathrm{x}$ in Figure 1) the cost of achieving any more equality becomes greater than the benefits of such a reduction in inequality.

Such 'benefits' are to be determined, of course, not by the economist but by those whose job it is to take decisions on the expenditure of NHS money. The most the economist can do at present is to suggest methods of characterizing those extra consultations (by age, by sex, by condition, and so on), which may be useful to the decision-maker in arriving at his own valuation, and to relate these changes to the cost of achieving them.

In discussing the effect of numbers of general practitioners on care provided, I have concentrated on one easily quantifiable aspect (namely, consultations) in order to illustrate the economic approach. This consists in quantifying the marginal (extra) effect of general practitioners, attempting to qualify these effects in such a way that the decision-maker can value them, and then relating these effects to the costs of achieving them. Other effects of list size on such things as time spent with each patient, referral behaviour, and so on might be more difficult to characterize in this way but could, in principle, be so approached.

Measurement of these aspects of patient/doctor behaviour is, of course, not the same thing as 
measurement of medical care or changes in health status. To this extent one is still measuring inputs and not outputs, but there are some methods of characterizing inputs which are more useful for relating to outputs than others.

\section{REMUNERATION AND ITS EFFECTS}

The method of remunerating general practitioners in the United Kingdom is normally referred to as a capitation method, but this, of course, is not strictly correct. Professor Abel-Smith once drew an analogy between the capitalist/communist division and the fee-for-service/salary division. If this is so, then nowhere is there more evidence of the UK's mixed economy than in its system of remunerating general practitioners.

Methods of payment can be regarded as running the gamut from salary at one end, through capitation fee and payment by case, to payment by item of service. The UK system stretches right along this gamut and indeed incorporates a number of payments which are difficult to characterize under any of these headings.

There is a basic practice allowance of $£ 1,815$, which is paid to all doctors with NHS lists above 1,000 , which constitutes the main salary element. There is a differential capitation fee of $£ 1.50$ for all patients under 65 and $£ 2 \cdot 10$ for all patients over 65 . The fee for treating temporary residents $(£ 1 \cdot 50$ or $£ 2 \cdot 25$, depending on just how temporary the resident is) can be seen as a case payment, i.e., the doctor is paid for seeing a patient during a period of time. Finally, the fees for performing vaccinations and immunizations $(£ 0.50$ or $£ 0.75)$, cervical cytology tests $(£ 1 \cdot 50)$, and night visits $(£ 3 \cdot 00)$ are fees for items of service.

In addition to the types of payment outlined above, there exist a number of payments designed to reward certain things. Such payments are, for example, the designated areas allowances ( $£ 490$ and $£ 750$ ) paid for practice from a main surgery in certain designated areas; the group practice allowance of $£ 270$ to encourage the formation of groups; a vocational training payment of $£ 400$ to encourage aspirant practitioners to follow a course of vocational training; and seniority payments (ranging up to £910) contingent on attendance at postgraduate courses.

Payments are also made to offset $70 \%$ to $80 \%$ of expenses for ancillary staff and premises. The attachment of local authority staff or the provision of health centre accommodation by local health departments also constitute a saving for the general practitioner.
A full catalogue of methods by which practitioners are paid (and the way in which expenses are allowed for) would take too long to recount. Our main interest, however, is to assess the effect of these methods on the behaviour of the general practitioner.

For the vast majority of practitioners the two most important elements in the payment system are the capitation fees and the basic practice allowance. In essence, therefore, the UK system of payment is akin to a two-part tariff, a base payment of $£ 1,815$, which is invariant above a list size of 1,000 , and a variable payment which (ignoring for the moment the distinction between under $65 \mathrm{~s}$ and over $65 \mathrm{~s}$ ) increases proportionately up to a maximum list size of 3,500 patients. Assuming away, for the moment, the existence of all other payments except the basic practice allowance and the capitation fee, the income schedule facing the practitioner would look as in Figure 2.

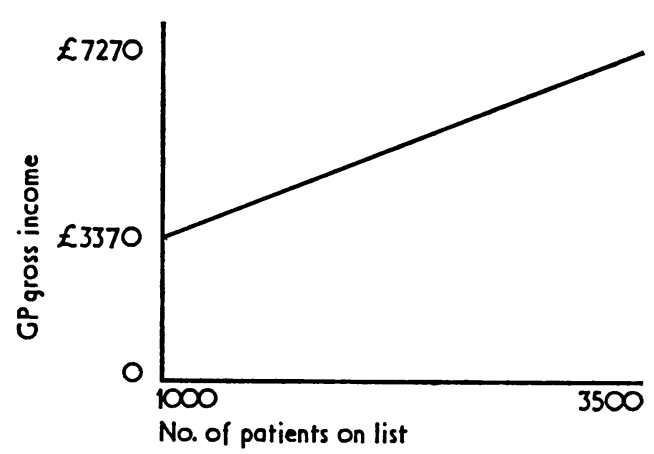

Fig. 2

If one assumes that general practitioners are prepared to exchange more income for more leisure time, then the effect of such a two-part tariff system is to discourage practitioners from taking on more patients compared with what they might do under a complete capitation fee system. If at some point they had the same number of patients and the same total income under both systems, then the incentive to take on an extra patient is obviously greater under a complete capitation fee system. An increase in list size from 2,500 to 3,000 increases a practitioner's income by $20 \%$ under a complete capitation fee system but only by $14 \%$ in our simplified two-part tariff system.

The two-part payment is a method of coping with one of the criticisms which is frequently made of a pure capitation system, namely, that it encourages doctors to acquire longer lists to the detriment of the quality of care they can provide. 
The advantages and disadvantages of capitation fees have been rehearsed in great detail in a number of publications (Hogarth, 1963; Glaser, 1970) and I shall attempt no more than a summary here. Capitation systems are normally preferred to salary systems by doctors. This is because a capitation system is more consistent with an independent professional status and because the system provides a means whereby, at any rate potentially, the income earned by a general practitioner can be related to the amount of work he undertakes, as measured by his list size. It was the recognition that over-65s generate more work than under-65s that led to the institution of a two-level capitation fee. I used the word 'potentially' because, as we have seen, there is evidence of a lower consultation rate among patients on larger lists, and Mechanic (1968) found that consultation times tended to be shorter in practices of larger size.

Another consequence of the capitation fee system is that a means is provided whereby the patient can exercise some influence directly over the quality of care provided by the doctor through the patient's ability to withdraw from the list and thus reduce the doctor's income. Conversely, the doctor who provides a service attractive to patients may increase his income. Capitation fees thus preserve an element of competition. Klein, in his recent study (1973), looked at the number of patients who changed their doctor without changing their address. He found rates varying from $2 \cdot 5$ per 1,000 patients per annum to 7 per 1,000 . Of course, one of the effects of the two-part payment system is to reduce the marginal impact of a patient leaving a doctor's list.

One of the most frequent criticisms of the capitation fee method of payment is that it encourages doctors to carry out fewer tasks themselves than other payment systems more related to work done. Critics allege that general practitioners have an incentive to refer their patients to outpatient clinics or casualty departments rather than dealing themselves with these patients. It is also alleged that general practitioners are encouraged by the capitation fee method to deal more hurriedly with their patients, leading to excessive prescribing.

A number of studies (Fry, 1960; Priest, 1962; Forsyth and Logan, 1968) confirm that many of the patients at outpatient clinics and in casualty departments could have been treated by their general practitioner. But to say that a patient could have been treated by his family doctor is not necessarily to say that he should have been, any more than to say that grapes can be grown in this country is to say that they should be grown in this country. The general practitioner also has the problem of how best to allocate his time among competing demands. He may judge that his absolute and comparative advantage (to use an economist's term) does not lie in diagnosing definitively and treating every patient he could to the neglect of other patients and tasks. The assumption that it must always be more 'economical' for a general practitioner to carry out a task than for it to be carried out at the hospital is just that-an assumption. I know of no evidence to support it. Indeed it is one of the basic problems of running an organization like the National Health Service that participants have little or no way of knowing the implications of their decisions for the use of resources.

Just as we might expect a capitation fee system to be subject to the criticism that it encourages general practitioners to do less work than somebody thinks they should, so a fee per item of service system tends to be criticized on the basis that it encourages practitioners to carry out more of those tasks for which there is a fee than somebody thinks they should.

The point here is simply that in an area like medical care, where it is unlikely that one could draw up standards of practice which are generally applicable and acceptable, perhaps the best solution is to have a system of payment which is sufficiently flexible that one can make minor adjustments to the range of incentives (as has been done for vaccination and cervical cytology) in order to bring practice in limited fields into line with generally agreed objectives. Monetary incentives are, of course, only one of the factors which influence clinicians' behaviour but they have the advantage of being comparatively easy to alter in the short run and of being reasonably certain in their effects.

The argument that a capitation fee encourages preventive medicine by providing an incentive to keep the patient well since he will then take up less of the doctor's time has fallen into disrepute. There appears to be little evidence that such 'prevention' has taken place under the NHS and it is not difficult to see why. There seems no reason to believe that, even if 'preventive' medicine prevented a significant amount of illness, this would result in any saving of family doctors' time. Most of the illnesses which 'preventive' medicine might be expected to forestall would probably be treated in hospital rather than by the general practitioner. The medical care system might have less work to do if preventive medicine was effective but it is unlikely that the general practitioner would.

Before leaving the subject of remuneration I should like to say one or two things about the geographical distribution of general practitioners. This has been 
the subject of a vast report by a team from the University of Kent, now published in a somewhat shorter version (Butler, Bevan, and Taylor, 1973). Since 1966 there have been explicit inducements for doctors to move to 'underdoctored' areas, roughly areas with an average list size above 2,500. This was added to the powers of negative direction enjoyed by the Medical Practices Committee and to the built-in incentive provided by a capitation system. (Once again, however, it should be noticed that the two-part payment system offsets this incentive.)

There has been increased dissatisfaction with the continuance of regional disparities in list sizes after 25 years of the NHS and suggestions that the present system has been ineffective. I have recently analysed the dispersion of average list sizes about their mean for 1952 and 1971 using a system which divided England into 26 geographical groups. The measure of dispersion used (the standard deviation) showed a decline between 1952 and 1971 of about $50 \%$ (the mean list sizes in the two years were 2,526 and 2,482), falling from 305 in 1952 to 156.

To establish the extent to which this decline was due to policy one would ideally need to run the years 1952 to 1971 again changing nothing but the payment and location arrangements for general practitioners. In the absence of $\mathbf{H}$. G. Wells all one can look for is some indication of how the trends in the distribution of general practitioners might have gone if a different system had been in effect. I have chosen to do this by looking at the regional distribution of general dental practitioners who are paid on a fee-for-service basis with a patient 'deductible' contribution, where there are no Medical Practices Committee and no designated area incentives.

Here the standard deviation has increased by some $60 \%$ between 1949 and 1971 and from 648 to 1,042 .

One can, perhaps, weakly conclude that the combination of measures to induce an even distribution of general practitioners have been relatively successful in so doing.

\section{Time AND Distance}

The National Health Service is usually characterized as a free-at-the-point-of-consumption service. But although the patient does not have to pay the doctor he still must expend time and effort to gain access to medical care. One aspect of this expenditure of time and effort is the journey from the patient's home or work to the doctor's surgery, the outpatient clinic or the casualty department. Although the importance of distance in determining the demand for medical care has long been recognized in the United States (Shannon, Bashshur, and Metzner, 1969) it has tended to be ignored in this country, being seen mainly as a problem of the elderly (Lance, 1971), or as requiring a mild modification of the case for 3,000-bed hospitals.

In fact, Morrell, Gage and Robinson (1970), in their study of patterns of demand in general practice, made the curiously neglected observation that the consultation rate for patients living less than fiveeighths of a mile from the practice was 5.0 compared with 3.6 for those living more than five-eighths, and this was not explicable on the basis of age, sex, or social class since these latter variables showed no association with distance.

Rosamond Gruer (1972), in her excellent study of outpatient services in the borders area of Scotland, has also looked at the effect of distance from the general practitioner. She found that the estimated referral rate of new outpatients by general practitioners was 10.0 per 1,000 population per year in the population who lived less than three miles away whereas in those who lived further away it was 5.6. She found a similar relationship between rate of referral and distance from the outpatient clinic.

Colleagues of mine at Newcastle have been looking at the choice patients make between attending at casualty with trauma and seeking the aid of their general practitioner. They found that the most important factor distinguishing the group attending the casualty department from those who sought their general practitioner's help was their relative nearness to the casualty department. Distance had played a large part in their choice.

All of this has many implications for the size and location of group practices, health centres, and hospitals. But it may also provide a means whereby health services can be valued relative to one another and to other forms of expenditure. To show how this may be so, the figure below represents an elementary economic concept: the demand curve (Fig. 3).

This curve illustrates that, as the price of a commodity falls, relatively more is demanded. The more money one must exchange for the product, the less one will purchase. The curve represents the preferences of a particular group or individual. At the price $P_{1}$ he will purchase $Q_{1}$ units of the commodity. Hence the last unit he buys is just worth $P_{1}$ to him. $P_{1}$ is the value of the last unit to him or to the group.

Some work I have done recently shows the following relationship between the distance patients live from outpatient clinics and the length of the outpatient episode (Fig. 4). 


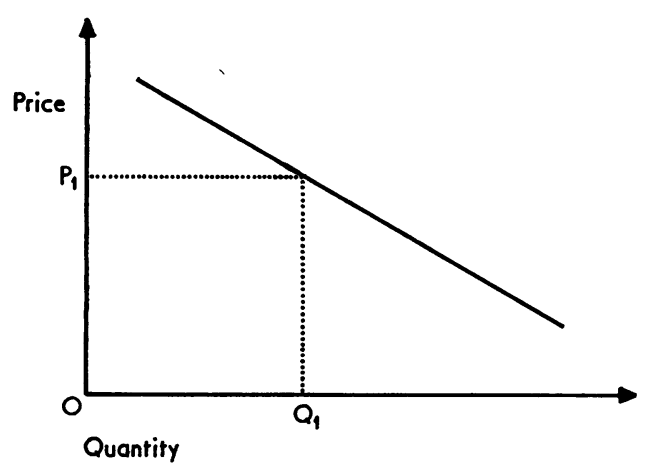

FIG. 3

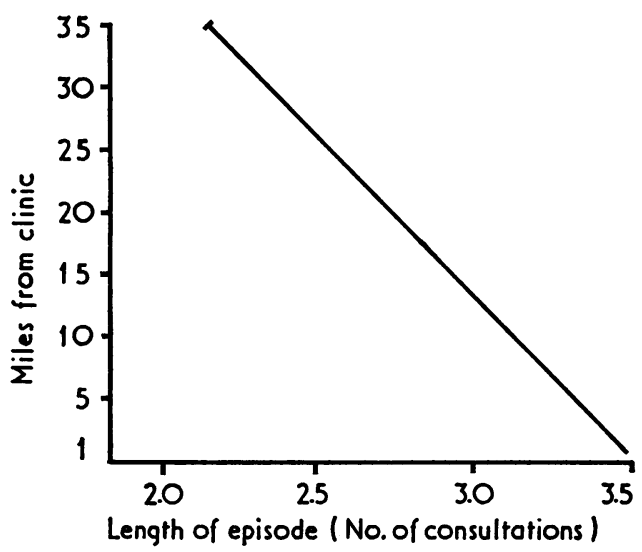

Fig. 4

Figure 4 shows that the nearer the patient lives to the clinic, the longer on average will be his outpatient episode. But it is also clear that this curve shows certain resemblances to a demand curve. The episode length can be interpreted as the quantity of outpatient care the patient receives. The distance from the clinic can be seen as the price the patient must pay to avail himself of outpatient care. The consultants (and the patients?) are clearly comparing the benefits of extra consultations with the cost in terms of extra time and effort which the patient must spend to acquire these benefits. And they are establishing a rate of exchange between these two. Implicitly, they are valuing the extra consultations.

The interesting thing about this valuation is that it does not rely on the patient assessing the value to him of extra consultations, a judgment he is not always qualified to make. It arises from the complex interaction of the doctor-patient relationship. The fact that non-attendances were unrelated to distance strengthens this view.

In this example, doctors (and patients?) show the rate at which they are prepared to exchange extra medical care for something else (in this case time and effort of patients), and this is the essence of what an economist means by value. Could a similar approach be applied to general practice? The evidence from Gruer and Morell suggests to me that it could, and that such an exercise could throw valuable light on the benefits of, for example, reductions in list size.

\section{Conclusions}

I have looked at three topics relevant to general practice in this country as viewed by an economist. Naturally in so short a time I have had to omit many topics (for example, the economic role of ancillary staff) which I should have liked to cover. Necessarily also I have had to treat those areas which I have looked at without the necessary qualifications, modifications or explanations. Economics provides above all a way of looking at problems with a view to making more explicit the consequences of choice involving scarce resources, and I hope that what I have had to say has been in line with this aim.

I am particularly grateful to participants at the Advanced Seminar on Health Economics at the London School of Hygiene and Tropical Medicine and to members of the University of Sheffield Economics Department for comments on an earlier draft of this paper.

\section{REFERENCES}

Butler, J. R., Bevan, J. M., and Taylor, R. C. (1973). Family Doctors and Public Policy. Routledge and Kegan Paul, London.

Cartwright, A. (1967). Patients and their Doctors. A Study of General Practice. Routledge and Kegan Paul, London.

Clarke, M. (1971). Changes in list size and the effect on the practitioner's workload. Update Plus, 1, 337.

CouncIL of THE R.C.G.P. (1973). Present State and Future Needs of General Practice, 3rd ed., p. 10. (Report from General Practice, 16).

Department of Health and Soctal Security. Annual Reports.

ForsYTH, G. and LOGAN, R. F. L. (1968). Gateway or Dividing Line? A study of hospital out-patients in the 1960s. Oxford University Press, London. 
FRY, L. (1960). Casualties and casuals. Lancet, 1, 163.

Glaser, W. A. (1970). Paying the Doctor. Systems of Remuneration and their Effects. The John Hopkins Press, Baltimore and London.

GRUER, R. (1972). Outpatient Services in the Scottish Border Counties. Scottish Home and Health Department. (Scottish Health Service Studies No. 23).

Hogarth, J. (1963). The Payment of the General Practitioner. Some European Comparisons. Oxford University Press, London.

KLEIN, R. (1973). Complaints against Doctors. A Study in Professional Accountability. Charles Knight, London.

LANCE, H. (1971). Report on transport services in general practice. An experiment in five general practices. J. roy. Coll. gen. Practit., Suppl., 3, 21.
Mechanic, D. (1968). General practice in England and Wales. Results from a survey of a national sample of general practitioners. Med. Care, 6, 245.,

Morrell, D. C., GaGe, H. G., and Robinson, N. A. (1970). Patterns of demand in general practice. J. roy. Coll. gen. Practit., 19, 331.

Priest, W. M. (1962). A thousand outpatients. Lancet, 2, 1043.

Shannon, G. W., Bashshur, R. L., and Metzner, C. A · (1969). The concept of distance as a factor in accessibility and utilization of health care Med. Care Rev., 26, 143.

WRIGHT, H. J. (1968). General practice in south-west England. Report of a survey of 68 practices in the south-west England Faculty of the Royal College of General Practitioners, 1964-65. Reports from General Practice No. 8. Council of the Royal College of General Practitioners. 